\title{
REVIEW
}

\section{Soluble adhesion molecules as markers for sepsis and the potential pathophysiological discrepancy in neonates, children and adults}

\author{
Rens Zonneveld ${ }^{1,2,3}$, Roberta Martinelli ${ }^{2}$, Nathan I Shapiro ${ }^{4}$, Taco W Kuijpers ${ }^{3}$, Frans B Plötz
} and Christopher $\vee$ Carman $^{2^{*}}$

\begin{abstract}
Sepsis is a severe and life-threatening systemic inflammatory response to infection that affects all populations and age groups. The pathophysiology of sepsis is associated with aberrant interaction between leukocytes and the vascular endothelium. As inflammation progresses, the adhesion molecules that mediate these interactions become shed from cell surfaces and accumulate in the blood as soluble isoforms that are being explored as potential prognostic disease biomarkers. We critically review the studies that have tested the predictive value of soluble adhesion molecules in sepsis pathophysiology with emphasis on age, as well as the underlying mechanisms and potential roles for inflammatory shedding. Five soluble adhesion molecules are associated with sepsis, specifically, E-selectin, L-selectin and P-selectin, intercellular adhesion molecule-1 and vascular cell adhesion molecule-1. While increased levels of these soluble adhesion molecules generally correlate well with the presence of sepsis, their degree of elevation is still poorly predictive of sepsis severity scores, outcome and mortality. Separate analyses of neonates, children and adults demonstrate significant age-dependent discrepancies in both basal and septic levels of circulating soluble adhesion molecules. Additionally, a range of both clinical and experimental studies suggests protective roles for adhesion molecule shedding that raise important questions about whether these should positively or negatively correlate with mortality. In conclusion, while predictive properties of soluble adhesion molecules have been researched intensively, their levels are still poorly predictive of sepsis outcome and mortality. We propose two novel directions for improving clinical utility of soluble adhesion molecules: the combined simultaneous analysis of levels of adhesion molecules and their sheddases; and taking age-related discrepancies into account. Further attention to these issues may provide better understanding of sepsis pathophysiology and increase the usefulness of soluble adhesion molecules as diagnostic and predictive biomarkers.
\end{abstract}

\section{Introduction}

Sepsis [1], due to its detrimental sequelae and limited therapeutic options, continues to be responsible for many deaths amongst all age groups [2-4]. Growing evidence indicates that aberrant leukocyte activation and recruitment into host tissues plays a pivotal role in causing breakdown of the vascular endothelium [5], which in turn leads to organ failure and death [6]. Inflammatory leukocyte recruitment is initiated by soluble mediators (for example, cytokines or bacterial-derived lipopolysaccharide (endotoxin)),

\footnotetext{
* Correspondence: ccarman@bidmc.harvard.edu

${ }^{2}$ Department of Medicine, Center for Vascular Biology Research, Beth Israel Deaconess Medical Center, Harvard Medical School, Boston, 330 Brookline Avenue, RN-234, Boston, MA 02215, USA

Full list of author information is available at the end of the article
}

which upregulate adhesion molecule expression on both leukocytes and the endothelium. This upregulation results in a multistep adhesion cascade whereby circulating immune cells sequentially roll on, firmly adhere to, and transmigrate across the endothelium [7-9]. During the progression of inflammatory responses, soluble isoforms of the leukocyte recruitment adhesion molecules are shed from cell surfaces and accumulate within the circulating blood plasma [10]. These soluble isoforms have been considered promising prognostic biomarkers of severity of inflammation but the clinical utility of monitoring such changes remains poor [11].

One reason for the thus far limited clinical utility of these soluble isoforms is the fact that shedding in 
general is neither a passive nor an inevitable consequence of upregulated expression/cell activation. Most shedding is an active process, which is discretely regulated by diverse proteolytic enzymes, although cell damage can also variably contribute to soluble adhesion molecule levels [10]. Although still a matter of controversy, there is increasing evidence that shedding serves regulatory roles to dampen inflammation (and specifically to reduce leukocyte-endothelial interactions) and protect the host from excessive collateral damage $[10,12]$. Furthermore, age-related differences in both levels of soluble adhesion molecules and the enzymes that mediate shedding have been observed in both healthy and septic patients (as discussed in detail below). The relationship between soluble adhesion molecule levels, underlying inflammatory and shedding activities and clinical outcomes may thus be more complex than once thought.

The goals of this review are therefore to summarize existing knowledge regarding the mechanisms and putative functions for shedding of cell surface adhesion molecules/ generation of soluble isoforms, unequivocally identified to exist at elevated levels in the blood of septic patients, and to investigate how these levels and their shedding differ amongst healthy and septic neonates, children and adults to improve our understanding and clinical utility of soluble adhesion molecules.

\section{Literature search}

We performed a comprehensive literature search in MEDLINE using medical subject headings and text words, supplemented by scanning the bibliographies of the recovered articles. We combined 'endothelium' and 'leukocytes' using the term 'OR'. This search was subsequently combined with 'sepsis' using the Boolean operator 'AND'. We used a similar search strategy, using the terms 'soluble' and 'circulating adhesion molecules'. We combined these results with the terms 'sepsis', 'septic shock', 'endothelium, 'leukocytes', 'monocytes', 'granulocytes', 'macrophages', 'neutrophils', 'lymphocytes' and 'inflammation'. We then combined these results with the terms 'children', 'neonates', 'adults' and 'age'.

\section{Soluble adhesion molecules: from cell surface to circulation}

Five soluble adhesion molecules were associated with sepsis and their main characteristics are summarized in Table 1. Three adhesion molecules (E-selectin, L-selectin and P-selectin) belong to the selectin superfamily and function in leukocyte rolling (Figure 1). Two adhesion molecules (intercellular adhesion molecule 1 (ICAM-1) and vascular cell adhesion molecule 1 (VCAM-1)) belong to the immunoglobin domain superfamily cell adhesion molecules that are important for firm adhesion and transendothelial migration [13]. In all cases, inflammatory mediators (for example, cytokines, thrombin, lipopolysaccharide) first increase cell surface expression of these molecules followed by the later appearance of shed, soluble isoforms (Table 1 and Figure 2).

\section{E-selectin}

Soluble isoforms of E-selectin can be found in the supernatant of endothelial cells cultured in vitro within 24 hours of cytokine activation and are generated through a largely caspase-dependent shedding process $[10,14-16]$. In healthy individuals low levels of soluble E-selectin (sE-selectin) are found in serum, but these levels are greatly elevated in septic patients [16,17]. Importantly, shed sE-selectin from sera of septic patients retained the ability to adhere to granulocytes in vitro [16]. Shedding of E-selectin has thus been proposed to limit leukocyteendothelial interactions both by decreasing the cell surface density on the endothelium and by generating an intravascular competitive inhibitor or decoy ligand (that is, sE-selectin) for leukocytes, thereby reducing collateral damage in the host [18]. Indeed, one clinical study found that while sE-selectin was elevated in septic children, those with the highest levels exhibited the best outcomes and survival rates [19].

Table 1 Characteristics of adhesion molecules involved in sepsis

\begin{tabular}{|c|c|c|c|c|c|c|}
\hline $\begin{array}{l}\text { Adhesion } \\
\text { molecule }\end{array}$ & Expression & Ligands & Inflammatory mediators & Mode of expression & Specific function & Sheddase \\
\hline E-selectin & Endothelial cells & ESLG-1, PSGL-1 & TNFa, LPS, IL-1 & Inducible & Rolling & Caspase \\
\hline L-selectin & Leukocytes & GlyCAM-1, MAdCAM-1 & TNFa, LPS, IL-1, IL-6 & Constitutive, inducible & Rolling & ADAM-17 \\
\hline P-selectin & $\begin{array}{l}\text { Endothelial cells, } \\
\text { platelets }\end{array}$ & PSGL-1 & $\begin{array}{l}\text { TNFa, IL-4, IL-13, histamine, } \\
\text { thrombin }\end{array}$ & Constitutive & Rolling & MMP \\
\hline ICAM-1 & Endothelial cells & Mac-1, LFA-1 & TNFa, LPS, IL-1 & Constitutive, inducible & Firm adhesion, TEM & ADAM-17, NE \\
\hline VCAM-1 & Endothelial cells & VLA-4 & TNFa, LPS, IL-1 & Constitutive, inducible & Firm adhesion, TEM & ADAM-17, NE \\
\hline
\end{tabular}

$A D A M$, a disintegrin and metalloproteinase; ESGL-1, endothelial selectin glycoprotein ligand; GlyCAM-1, glycosylation dependent cell adhesion molecule; ICAM-1, intercellular adhesion molecule-1; IL, interleukin; LFA, leukocyte function antigen; LPS, lipopolysaccharide; Mac, macrophage antigen; MAdCAM, mucosal vascular addressin cell adhesion molecule; MMP, matrix metalloproteinase; NE, neutrophil elastase; PSGL, platelet selectin glycoprotein ligand; TEM, transendothelial migration; $T N F$, tumor necrosis factor; $V C A M-1$, vascular cell adhesion molecule-1; VLA, very late antigen. 


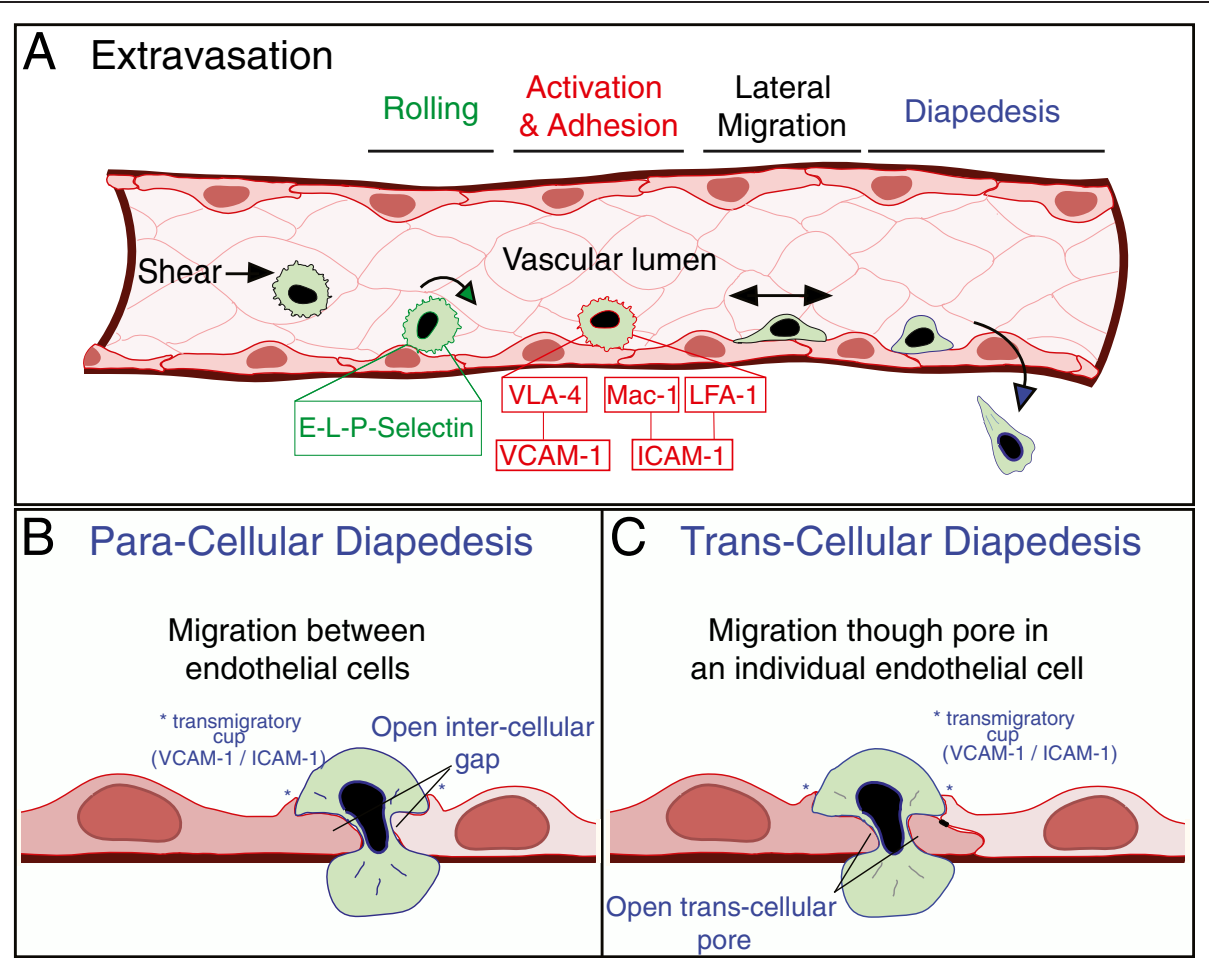

Figure 1 Stages of extravasation of a leukocyte. (A) Leukocytes first undergo tethering and rolling on the endothelium, mediated by E-selectin, L-selectin, and P-selectin and their carbohydrate ligands. Activation and adhesion: leukocyte rolling facilitates interaction with chemoattractants present on endothelial surfaces, which in turn causes leukocyte activation that triggers firm adhesion and arrest, mediated by the integrins macrophage-1 (Mac-1), leukocyte function antigen-1 (LFA-1) and very late antigen-4 (VLA-4) binding to their endothelial ligands intercellular adhesion molecule-1 (ICAM-1) and vascular cell adhesion molecule-1 (VCAM-1). Subsequently, leukocytes engage in lateral migration over the endothelial wall in search of a site to transmigrate, guided by VCAM-1/ICAM-1-enriched transmigratory cups (asterisks in (B) and (C)), present on endothelial cells. The last step in this cascade is transendothelial migration or diapedesis, whereby the leukocytes cross the endothelial barrier, either (B) paracellular, through the interendothelial junctions, or (C) transcellular, via the formation of a transcellular pore. See [7-9,13] for additional details.

\section{L-selectin}

Within approximately 10 to 15 minutes of leukocyte activation by cytokines (for example, tumor necrosis factor alpha) or lipopolysaccharide, soluble L-selectin (sL-selectin) is measurable in the blood plasma as a result of cleavage by a disintegrin and metalloproteinase (ADAM)-17 [10,20,21]. Clinical studies show that L-selectin is shed and detected at elevated levels in the plasma during the systemic inflammatory response [22]. Interestingly, Seidelin and colleagues [22] found that the greatest survival was among septic adults that presented with the highest levels of sL-selectin, and similar findings were made in another study focused on children [19]. Additionally, in an in vitro fluid shear flow model, exogenously added sL-selectin inhibited leukocyte rolling and firm adhesion to the endothelium in a dosedependent manner, presumably by competing with cell surface L-selectin for binding of endothelial ligands [23]. Moreover, Ferri and colleagues have demonstrated that systemic administration of exogenous sL-selectin to mice in vivo reduced intravascular leukocyte rolling and adhesion, and as a consequence decreased vascular leak in models of both local inflammation and sepsis [24-26].
Alternatively, addition of a small molecule inhibitor of shedding increased leukocyte adhesion and vascular leak in the same settings [26]. The authors thus propose a significant protective role for L-selectin shedding in sepsis.

\section{P-selectin}

P-selectin is found within both endothelial cells and platelets $[27,28]$. As with the other selectins, P-selectin can be measured in its soluble form in cell culture supernatants and in blood plasma, with greater levels found in septic patient plasma [29]. Mechanisms for P-selectin shedding remain poorly characterized, although some experimental data show that shedding of P-selectin might occur through cleavage by matrix metalloproteinase in patients with cardiovascular disease or hypertension $[30,31]$. The degree to which plasma soluble P-selectin (sP-selectin) is derived from endothelial cells versus platelets remains unclear. However, one study found a strong positive correlation between coagulation (disseminated intravascular coagulation, fibrinogen consumption and thrombin activation markers) and sP-selectin in septic patients, indicating a significant 

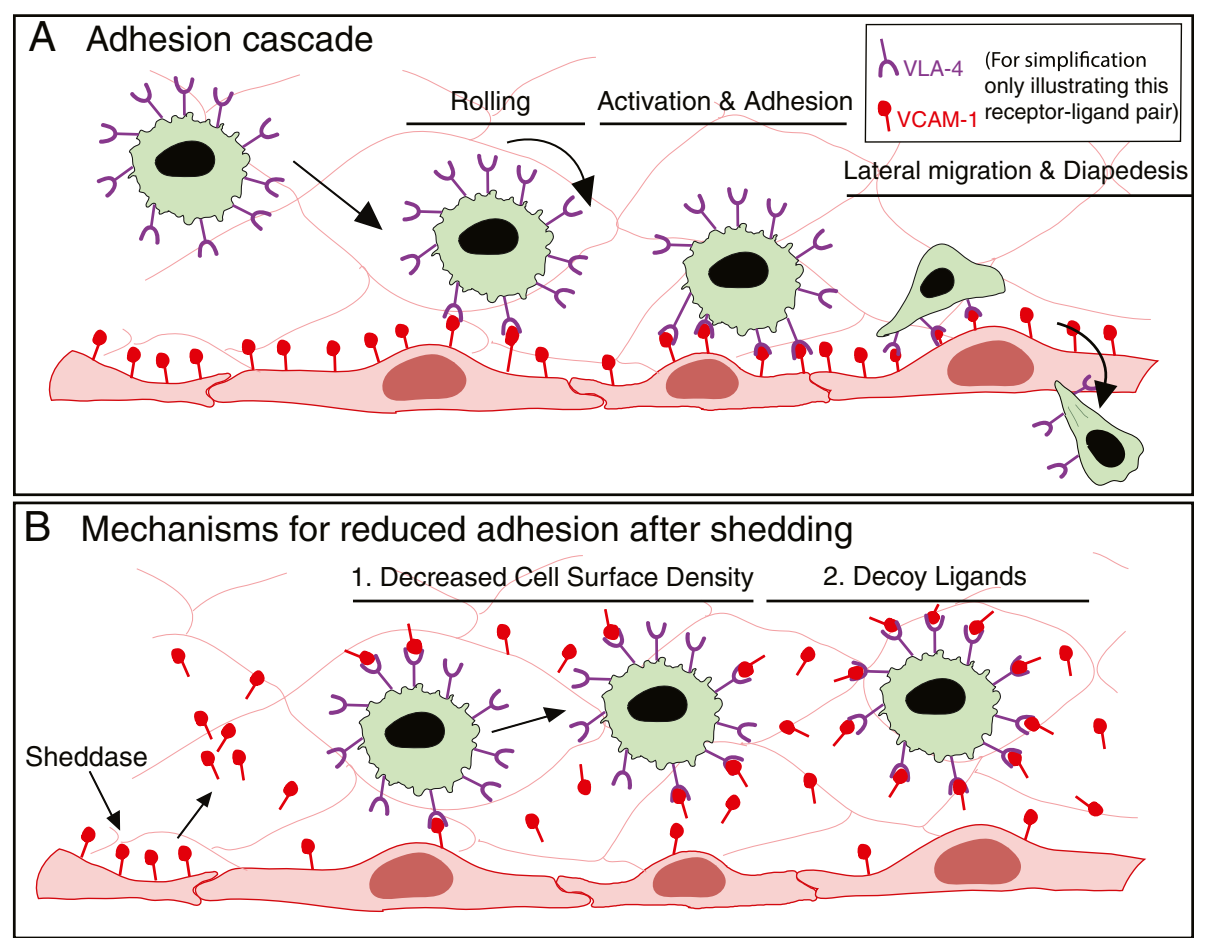

Figure 2 Shedding of selectin and immunoglobulin superfamily adhesion molecules and its functional implications. For simplification, only one example receptor ligand pair (very late antigen-4 (VLA-4)/vascular cell adhesion molecule-1 (VCAM-1)) is illustrated. (A) Interactions of cell surface integrin VLA-4, present on leukocytes, with endothelial cell surface VCAM-1 during different steps in the leukocyte adhesion cascade. (B) Ectodomain shedding of cell surface VCAM-1 (thereby generating the soluble isoform SVCAM-1) by sheddases might reduce leukocyte adhesion to the endothelium on two complementary levels: reduction of cell surface density of adhesion molecules (for example, decreased endothelial cell surface VCAM-1, in this example); and binding of the resulting soluble isoforms to cell surface ligands (that is, binding of sVCAM-1 to leukocyte cell surface VLA-4 in this example), thereby serving as competitive antagonists (or decoy ligands) for the remaining cell-surface adhesion receptors. See [10] and the text for more details on functional implications of shedding.

role for platelet shedding of P-selectin [32]. Independently of its sources, sP-selectin could negatively modulate direct leukocyte-endothelial interactions and/or indirect plateletmediated secondary capture of leukocytes on the endothelium (both of which are dependent on P-selectin-platelet selectin glycoprotein ligand-1 adhesion), although this remains to be tested directly [28].

\section{Intercellular adhesion molecule-1}

In vitro 1 to 6 hours after activation of endothelial cells by cytokines, soluble ICAM-1 (sICAM-1) can be measured in culture supernatants, after shedding mediated by neutrophil elastase-dependent, ADAM-17-dependent and matrix metalloproteinase-9-dependent shedding [10,33-35]. Shedding of ICAM-1 is thought to promote detachment of leukocytes from the endothelium, thus limiting local inflammation [10]. Indeed, addition of exogenous neutrophil elastase was shown to be highly effective at cleaving surface-bound human ICAM-1 in vitro, which in turn abrogated Mac-1-dependent leukocyte adhesion [36]. Evidence supports a potentially protective role for ICAM-1 shedding during sepsis.
Elevated levels of sICAM-1 are well documented in human sepsis $[5,6,11]$, and studies performed in both humans and mice demonstrate that this is induced within $\sim 4$ hours of endotoxin challenge [37-39]. Significantly, septic children with the highest levels of sICAM-1 had better outcomes/survival rates [19], suggesting that shedding and loss of cell surface ICAM-1 from the endothelium may serve a protective function. Interestingly, in a cecal ligation puncture model of sepsis, ICAM-1-knockout mice - whereby cell-surface ICAM-1 is completely abolished - exhibited a significant decrease in leukocyte tissue invasion, organ damage and mortality compared with wild-type mice [37].

\section{Vascular cell adhesion molecule-1}

In vitro 1 to 6 hours after cytokine activation, VCAM-1 is measurable in its soluble form (sVCAM-1) in endothelial cell supernatant through shedding mediated by ADAM-17, cathepsin G and neutrophil elastase [10]. Singh and colleagues demonstrate that this may be achieved, at least in part, through the cytokine-mediated (that is, interleukin-1 $\beta$-mediated and tumor necrosis 
factor alpha-mediated) downregulation of tissue inhibitor metalloproteinase-3, which they showed to function as a tonic suppressor of ADAM-17-mediated VCAM-1 shedding [40]. In response to endotoxin, sVCAM-1 was observed to be markedly elevated in mice [38] and humans [39]. Furthermore, increased levels of sVCAM-1 are reported in human sepsis, and higher levels seem to be associated with increased severity of disease and nonsurvival [5,6]. Shedding of VCAM-1 is implicated to counteract the pro-adhesive state of leukocytes to the endothelium both by lowering endothelial receptor density [10] and by forming SVCAM-1 to act as a competitive inhibitor (or decoy receptor) of leukocyte very late antigen-4 [40,41] (Figure 2). Interestingly, prednisolone - a synthetic glucocorticoid shown to be beneficial in the treatment of sepsis - was shown to enhance sVCAM-1 levels, suggesting the intriguing possibility that its mechanism of action may be at least partially related to potentiation of VCAM-1 shedding [39].

\section{Levels of soluble adhesion molecules: impact of age Neonates}

Basal levels of all soluble adhesion molecules of healthy neonates are comparable with (sICAM-1) or higher than

Table 2 Levels of soluble E-selectin in neonates, children and adults

\begin{tabular}{|c|c|c|c|c|c|c|}
\hline Study (reference) & Mean age & Sepsis criteria & Healthy $(\mu \mathrm{g} / \mathrm{ml})^{\mathrm{a}}$ & $\begin{array}{l}\text { Number } \\
\text { of patients } \\
\text { (healthy) }\end{array}$ & Sepsis $(\mu \mathrm{g} / \mathrm{ml})^{\mathrm{a}}$ & $\begin{array}{l}\text { Number } \\
\text { of patients } \\
\text { (sepsis) }\end{array}$ \\
\hline \multicolumn{7}{|l|}{ Neonates } \\
\hline Dollner and colleagues [52] & 0 to 7 days & Clinical & 91.4 (2 to 217.8) & 24 & 151.7 (37 to 362.2) & 18 \\
\hline Austgulen and colleagues [45] & Pre/at term & Clinical & 134.1 (69.5 to 280$)$ & 168 & 187.7 (118.4 to 262.2) & 24 \\
\hline Edgar and colleagues [57] & 0 to 7 days & Clinical & $71(51$ to 118$)$ & 27 & 135 (94 to 192$)$ & 192 \\
\hline Giannaki and colleagues [47] & At term & Clinical & $139 \pm 48$ & 40 & & \\
\hline Edgar and colleagues [55] & At term & Clinical & $71(51$ to 118$)$ & 46 & 158 (94 to 207) & 46 \\
\hline \multicolumn{7}{|l|}{ Children } \\
\hline \multirow[t]{2}{*}{ Andrys and colleagues [60] } & 6 to 10 & & 57.6 (36.7 to 152.2$)$ & 68 & & \\
\hline & 11 to 15 & & 42.1 (29.9 to 114.1$)$ & 90 & & \\
\hline Paize and colleagues [61] & 2 to 16 & PRISM & $100(90$ to 110$)$ & 40 & 230 (100 to 380$)$ & 20 \\
\hline Krueger and colleagues [62] & $3.5(0.2$ to 16$)$ & ACCP/SCCM & 68 (49 to 105$)$ & 22 & 131 (112 to 146$)$ & 22 \\
\hline Whalen and colleagues [63] & 1 day to 17 years & $\begin{array}{l}\text { Criteria of Doughty } \\
\text { and colleagues }\end{array}$ & $46 \pm 6$ & 14 & 230 & 77 \\
\hline \multirow[t]{2}{*}{ Nash and colleagues [64] } & 9 & & $70(35$ to 121$)$ & 81 & & \\
\hline & 15 & & 59 (25 to 119$)$ & & & \\
\hline Briassoulis and colleagues [19] & $6.5(2.8)$ & PRISM & $161 \pm 43$ & 10 & $936 \pm 399$ & 10 \\
\hline \multicolumn{7}{|l|}{ Adults } \\
\hline Presterl and colleagues [65] & 51 (30 to 67 ) & APACHE II & $48.9(14.3$ to 89.9$)$ & 20 & $130(40$ to 570$)$ & 20 \\
\hline Weigand and colleagues [66] & $58.7(4.4)$ & ACCP/SCCM & 29 (14.3 to 89.9$)$ & 7 & 85 & 14 \\
\hline Hynninen and colleagues [67] & $49(17.2)$ & APACHE ॥ & & & 73 (62 to 89) & 11 \\
\hline Knapp and colleagues [68] & 51 (21 to 96$)$ & APACHE III & $43.7 \pm 20.3$ & 15 & $94.5 \pm 54$ & 28 \\
\hline Osmanovic and colleagues [69] & Adult & & $28.5 \pm 14.3$ & 18 & $118 \pm 84$ & 9 \\
\hline Soderquist and colleagues [70] & 71 (10 to 91) & Unknown & 48 (20 to 97$)$ & 15 & 80 (22 to 200$)$ & 41 \\
\hline Takala and colleagues [71] & 44 to 59 (17 to 86$)$ & APACHE II & 45 (10 to 100$)$ & Unknown & 154 (61 to 394$)$ & 20 \\
\hline Geppert and colleagues [72] & 59 (35 to 85$)$ & SIRS & $42.8 \pm 19.4$ & 7 & $96.2 \pm 47.3$ & 27 \\
\hline De Pablo and colleagues [73] & $61.2(3.2)$ & APACHE ॥ & 48 & 36 & 98 & 52 \\
\hline Kayal and colleagues [74] & $57.2(3.9)$ & ACCP/SCCM & $40.5 \pm 4.5$ & 9 & $231 \pm 41.8$ & 25 \\
\hline Shapiro and colleagues [6] & $57(19)$ & APACHE III & 49 & 207 & 95 & 13 \\
\hline Andrys and colleagues [60] & 46 & & 54.3 (8.3 to 116.9$)$ & 68 & & \\
\hline Giannaki and colleagues [47] & Adult & & $48 \pm 13$ & 40 & & \\
\hline
\end{tabular}

$\overline{A C C P / S C C M}$, American college of chest physicians/society of critical care medicine; APACHE, acute physiology and chronic health evaluation; PRISM, pediatric risk of mortality; SIRS, systemic inflammatory response syndrome. ${ }^{\mathrm{a}}$ Data presented as mean (range) or mean \pm standard deviation. ${ }^{\mathrm{b}} \mathrm{Criteria}$ from [75]. Ages expressed in years unless otherwise stated. 
Table 3 Levels of soluble L-selectin in neonates, children and adults

\begin{tabular}{|c|c|c|c|c|c|c|}
\hline Study (reference) & Mean age & Sepsis criteria & Healthy $(\mu \mathrm{g} / \mathrm{ml})^{\mathrm{a}}$ & $\begin{array}{l}\text { Number } \\
\text { of patients } \\
\text { (healthy) }\end{array}$ & Sepsis $(\mu \mathrm{g} / \mathrm{ml})^{\mathrm{a}}$ & $\begin{array}{l}\text { Number } \\
\text { of patients } \\
\text { (sepsis) }\end{array}$ \\
\hline \multicolumn{7}{|l|}{ Neonates } \\
\hline Figueras-Aloy and colleagues [49] & 0 to 14 days & SNAP-II & 580 (523 to 717$)$ & 12 & 681 (541 to 757$)$ & 15 \\
\hline Kourtis and colleagues [50] & 0 to 2 days & Clinical & 1,155 & 75 & $1,331(1,123$ to 1,427$)$ & 14 \\
\hline Giannaki and colleagues [47] & At term & & $674 \pm 223$ & 40 & & \\
\hline Rebuck and colleagues [43] & At term & & 463 (338 to 557) & 22 & & \\
\hline Koenig and colleagues [42] & 0 to 7 days & & $324 \pm 24$ & 10 & & \\
\hline \multicolumn{7}{|l|}{ Children } \\
\hline Kourtis and colleagues [59] & Children & & $3,356(2,818$ to 3,894$)$ & 100 & & \\
\hline Briassoulis and colleagues [19] & $6.5(2.8)$ & PRISM & $3,750 \pm 321$ & 10 & $6,263 \pm 3,813$ & 10 \\
\hline \multicolumn{7}{|l|}{ Adults } \\
\hline Weigand and colleagues [66] & $58.7(4.4)$ & ACCP/SCCM & 460 & 7 & 400 & 14 \\
\hline Kourtis and colleagues [50] & Adult & & 950 (700 to 1,220$)$ & 75 & & \\
\hline Schleiffenbaum and colleagues [23] & Adult & & $1,600 \pm 800$ & 63 & & \\
\hline Giannaki and colleagues [47] & Adult & & $938 \pm 181$ & 40 & & \\
\hline Rebuck and colleagues [43] & Adult & & 717 (410 to 822 ) & 22 & & \\
\hline Koenig and colleagues [42] & Adult & & $537 \pm 28$ & 9 & & \\
\hline
\end{tabular}

ACCP/SCCM, American college of chest physicians/society of critical care medicine; PRISM, pediatric risk of mortality; SNAP, score for neonatal acute physiology.

${ }^{a}$ Data presented as mean (range) or mean \pm standard deviation. Ages expressed in years unless otherwise stated.

(sE-selectin, sP-selectin and sVCAM-1) basal levels in children or adults (Tables 2, 3, 4, 5 and 6 and Figure 3). Only the levels of sL-selectin are lower in neonates than in children or adults. Importantly, in neonatal sepsis, levels of all soluble molecules are increased, but both the relative and absolute extent of increase is remarkably lower compared with adults or children (Tables 2, 3, 4, 5 and 6 and Figure 3). This raises the important question of whether neonates are less effective at shedding or less avidly upregulate adhesion molecules in the first place. Indeed, some studies have been conducted to directly address this issue, which suggests contributions from both of these mechanisms. Cell surface levels of L-selectin on neutrophils and sL-selectin levels from cord blood were both lower than the cell surface and the circulating form of L-selectin found in adult blood [42-44]. Interestingly,

Table 4 Levels of soluble P-selectin in neonates, children and adults

\begin{tabular}{|c|c|c|c|c|c|c|}
\hline Study (reference) & Mean age & Sepsis criteria & Healthy $(\mu \mathrm{g} / \mathrm{ml})^{\mathrm{a}}$ & $\begin{array}{l}\text { Number } \\
\text { of patients } \\
\text { (healthy) }\end{array}$ & Sepsis $(\mu \mathrm{g} / \mathrm{ml})^{\mathrm{a}}$ & $\begin{array}{l}\text { Number } \\
\text { of patients } \\
\text { (sepsis) }\end{array}$ \\
\hline \multicolumn{7}{|l|}{ Neonates } \\
\hline Figueras-Aloy and colleagues [49] & 0 to 14 days & SNAP-II & 272 (152 to 288) & 12 & 244 (170 to 324$)$ & 15 \\
\hline Sitaru and colleagues [48] & 0 days & Clinical & $104 \pm 71$ & 10 & $222 \pm 128$ & 9 \\
\hline \multicolumn{7}{|l|}{ Children } \\
\hline Paize and colleagues [61] & 2 to 16 & PRISM & 50 (44 to 60$)$ & 40 & 61 (47 to 119) & 20 \\
\hline \multicolumn{7}{|l|}{ Adults } \\
\hline Mosad and colleagues [32] & 3 & SIRS/SOFA & $28.6 \pm 6$ & & $63 \pm 9$ & 176 \\
\hline Fijnheer and colleagues [29] & Adult & SIRS & $122 \pm 38$ & 10 & $398 \pm 203$ & 26 \\
\hline Weigand and colleagues [66] & $58.7(4.4)$ & ACCP/SCCM & $32.1 \pm 5.1$ & 7 & $296 \pm 56$ & 14 \\
\hline Osmanovic and colleagues [69] & Adult & Unknown & $181 \pm 44$ & 18 & $305 \pm 158$ & 9 \\
\hline Geppert and colleagues [72] & 59 (35 to 85$)$ & SIRS & $116.9 \pm 33.4$ & 7 & $291 \pm 227.4$ & 27 \\
\hline Leone and colleagues [76] & 45 to 47 (16 to 21$)$ & SIRS & $62 \pm 20$ & 26 & $129 \pm 98$ & 11 \\
\hline
\end{tabular}

ACCP/SCCM, American college of chest physicians/society of critical care medicine; PRISM, pediatric risk of mortality; SIRS, systemic inflammatory response syndrome; SNAP, score for neonatal acute physiology; SOFA, sequential organ failure assessment. ${ }^{a}$ Data presented as mean (range) or mean \pm standard deviation. Ages expressed in years unless otherwise stated. 
Table 5 Levels of soluble intercellular adhesion molecule- 1 in neonates, children and adults

\begin{tabular}{|c|c|c|c|c|c|c|}
\hline Study (reference) & Mean age & Sepsis criteria & Healthy $(\mu \mathrm{g} / \mathrm{ml})^{\mathrm{a}}$ & $\begin{array}{l}\text { Number } \\
\text { of patients } \\
\text { (healthy) }\end{array}$ & Sepsis $(\mu \mathrm{g} / \mathrm{ml})^{\mathrm{a}}$ & $\begin{array}{l}\text { Number } \\
\text { of patients } \\
\text { (sepsis) }\end{array}$ \\
\hline \multicolumn{7}{|l|}{ Neonates } \\
\hline Figueras-Aloy and colleagues [49] & 0 to 14 days & SNAP-II & 215 (156 to 274$)$ & 12 & 426 (394 to 458) & 15 \\
\hline Apostolou and colleagues [58] & At term & Clinical & $358.4 \pm 28.9$ & 10 & $710.7 \pm 56.6$ & 10 \\
\hline Dollner and colleagues [52] & 0 to 7 days & Clinical & 244 (95.2 to 500$)$ & 24 & 413 (255.6 to 500$)$ & 18 \\
\hline Austgulen and colleagues [45] & Pre/at term & Clinical & 258.8 (94 to 500$)$ & 168 & 394.2 (197.5 to 500$)$ & 24 \\
\hline Berner and colleagues [51] & 0 to 3 days & Clinical & 421 (291 to 459) & 35 & 446 (171 to 534$)$ & 136 \\
\hline Edgar and colleagues [57] & 0 to 7 days & Clinical & 165 (130 to 290$)$ & 27 & 341 (236 to 554$)$ & 192 \\
\hline Edgar and colleagues [56] & 0 to 7 days & Clinical & 205 & 46 & 406 & 46 \\
\hline \multicolumn{7}{|l|}{ Children } \\
\hline \multirow[t]{2}{*}{ Andrys and colleagues [60] } & 6 to 10 & & 346.8 (206.8 to 486.8 ) & 68 & & \\
\hline & 11 to 15 & & 269 (184.1 to 354$)$ & 90 & & \\
\hline Paize and colleagues [61] & 2 to 16 & PRISM & 260 (240 to 300$)$ & 40 & 705 (400 to 850$)$ & 20 \\
\hline Whalen and colleagues [63] & 1 day to 17 years & $\begin{array}{l}\text { Criteria of Doughty } \\
\text { and colleagues }\end{array}$ & $205 \pm 29$ & 14 & 595 & 77 \\
\hline \multirow[t]{2}{*}{ Nash and colleagues [64] } & 9 & & $310(280$ to 410$)$ & 81 & & \\
\hline & 15 & & 300 (270 to 390$)$ & & & \\
\hline Briassoulis and colleagues [19] & $6.5(2.8)$ & PRISM & $199 \pm 98$ & 10 & $172 \pm 93$ & 10 \\
\hline \multicolumn{7}{|l|}{ Adults } \\
\hline Weigand and colleagues [66] & $58.7(4.4)$ & $\mathrm{ACCP} / \mathrm{SCCM}$ & 190 & 7 & 1,100 & 14 \\
\hline Soderquist and colleagues [70] & 71 (10 to 91) & Unknown & 202 (62 to 392) & 15 & $451(216$ to 1,030$)$ & 41 \\
\hline Scherpereel and colleagues [77] & $58.9(14.9)$ & SAPS $\|$ & & & 2,130 & 63 \\
\hline Hofer and colleagues [78] & $65.9(12.4)$ & APACHE II & 219.6 (195.2 to 285.1$)$ & 108 & 444.7 (330 to 665.5) & 18 \\
\hline De Pablo and colleagues [73] & $61.2(3.2)$ & APACHE ॥ & 480 & 36 & 1100 & 52 \\
\hline Kayal and colleagues [74] & $57.2(3.9)$ & $\mathrm{ACCP} / \mathrm{SCCM}$ & $208 \pm 20.5$ & 9 & $868 \pm 131$ & 25 \\
\hline Shapiro and colleagues [6] & $57(19)$ & APACHE III & 185 & 207 & 240 & 13 \\
\hline Andrys and colleagues [60] & 46 & & 140 (60.2 to 218.4$)$ & 68 & & \\
\hline Leone and colleagues [76] & 45 to 47 (16 to 21$)$ & SIRS & 151 & 26 & 824 & 11 \\
\hline
\end{tabular}

ACCP/SCCM, American college of chest physicians/ society of critical care medicine; $A P A C H E$, acute physiology and chronic health evaluation; PRISM, pediatric risk of mortality; SAPS, simplified acute physiology score; SIRS, systemic inflammatory response syndrome; SNAP, score for neonatal acute physiology. ${ }^{a}$ Data presented as mean (range) or mean \pm standard deviation. ${ }^{b}$ Criteria from [75]. Ages expressed in years unless otherwise stated.

when challenged with neutrophil-activating chemoattractants, neonatal neutrophils exhibited a significantly lower shedding response compared with adult neutrophils $[42,43]$. Austgulen and colleagues suggest that these differences may be a reflection of a developing immune system [45] that shows features of hyporesponsiveness [46]. Since neonatal sepsis/infection is particularly difficult to diagnose and no dependable predictors exist, sE-selectin $[45,47,48]$, sL-selectin $[49,50]$ and sP-selectin $[48,49]$ as well as sICAM-1 [50-59] and sVCAM-1 [49] were evaluated as markers for the presence of infection in neonates. However, none of these soluble isoforms were introduced in a clinical setting because they did not reach predictive ability. The above discussion (and additional elaborations below) points toward complexities that need to be resolved before meaningful interpretations can be made.

\section{Children}

Generally speaking, the basal levels of soluble adhesion molecules in healthy children are similar to or lower than those of adults and neonates. However, both the relative amount and the absolute amount of sE-selectin and sL-selectin during sepsis seem much higher, whereas sP-selectin levels remain low. On the other hand, sICAM-1 and sVCAM-1 have similar basal levels and sepsis generates comparable or higher levels versus adults (Tables 2, 3, 4, 5 and 6 and Figure 3). Three studies assessed age-dependent differences in levels of selectins in healthy children $[59,60,64]$. Interestingly, infants 
Table 6 Levels of soluble vascular cell adhesion molecule- 1 in neonates, children and adults

\begin{tabular}{|c|c|c|c|c|c|c|}
\hline Study (reference) & Mean age & Sepsis criteria & Healthy $(\mu \mathrm{g} / \mathrm{ml})^{\mathrm{a}}$ & $\begin{array}{l}\text { Number } \\
\text { of patients } \\
\text { (healthy) }\end{array}$ & Sepsis $(\mu \mathrm{g} / \mathrm{ml})^{\mathrm{a}}$ & $\begin{array}{l}\text { Number } \\
\text { of patients } \\
\text { (sepsis) }\end{array}$ \\
\hline \multicolumn{7}{|l|}{ Neonates } \\
\hline Figueras-Aloy and colleagues [49] & 0 to 14 days & SNAP-II & 928 (856 to 1,005$)$ & 12 & $1,112(1,072$ to 1,153$)$ & 15 \\
\hline Austgulen and colleagues [45] & 0 to 7 days & Clinical & $1,940(1,100$ to 3,500$)$ & 168 & $1,950(1,190$ to 3,495$)$ & 24 \\
\hline \multicolumn{7}{|l|}{ Children } \\
\hline Andrys and colleagues [60] & 6 to 15 years & & 590.8 (359.6 to 822.0) & 68 & & \\
\hline Paize and colleagues [61] & 2.16 & PRISM & 600 (390 to 790$)$ & 40 & $1,550(1,360$ to 1,910$)$ & 20 \\
\hline Krueger and colleagues [62] & $3.5(0.2$ to 16$)$ & ACCP/SCCM & 766 (644 to 915$)$ & 22 & $1,239(928$ to 1,615$)$ & 22 \\
\hline Whalen and colleagues [63] & 1 day to 17 years & $\begin{array}{l}\text { Criteria of Doughty } \\
\text { and colleagues }\end{array}$ & $231 \pm 46$ & 14 & 600 & 77 \\
\hline \multirow[t]{2}{*}{ Nash and colleagues [64] } & 9 years & & $790(580$ to 1,060$)$ & 81 & & \\
\hline & 15 years & & $780(420$ to 1,000$)$ & & & \\
\hline \multicolumn{7}{|l|}{ Adults } \\
\hline Presterl and colleagues [65] & 51 & APACHE ॥ & 545 (374 to 829$)$ & 20 & 2633 & 20 \\
\hline Knapp and colleagues [68] & 51 to 55 (21 to 96$)$ & APACHE III & $569 \pm 98$ & 15 & $1,395 \pm 801$ & 28 \\
\hline Soderquist and colleagues [70] & 71 (10 to 91) & Unknown & 533 (354 to 1,018$)$ & 15 & $1,173$ (525 to 3,500$)$ & 41 \\
\hline Hofer and colleagues [78] & $65.9(12.4)$ & APACHE ॥ & $\begin{array}{l}1,524.7(991.2 \\
\text { to } 2,038)\end{array}$ & 108 & $\begin{array}{l}1,147.9 \text { (883.5 to } \\
2,074.4)\end{array}$ & 18 \\
\hline De Pablo and colleagues [73] & $61.2(3.2)$ & APACHE ॥ & 890 & 48 & 1,600 & 52 \\
\hline Shapiro and colleagues [6] & $57(19)$ & APACHE III & 1,050 & 49 & 1,550 & 95 \\
\hline Andrys and colleagues [60] & 46 & & 743 (338 to 1,148$)$ & 68 & & \\
\hline Leone and colleagues [76] & 45 to 47 (16 to 21 ) & SIRS & $458 \pm 123$ & 26 & $1,604 \pm 940$ & 11 \\
\hline
\end{tabular}

ACCP/SCCM, American college of chest physicians/ society of critical care medicine; APACHE, acute physiology and chronic health evaluation; PRISM, pediatric risk of mortality; SIRS, systemic inflammatory response syndrome; SNAP, score for neonatal acute physiology. ${ }^{\mathrm{a} D a t a}$ presented as mean (range) or mean \pm standard deviation. ${ }^{b}$ Criteria from [75]. Ages expressed in years unless otherwise stated.

had significantly lower levels of sL-selectin when compared with toddlers (average age 2 years) [59]. Additionally, healthy children (age 9 to 15.5 years) were found to have significantly decreasing sE-selectin levels with increasing age [64]. The authors of all three studies suggest that potential developmental changes exist in both expression and shedding of selectins, but that the physiological relevance of these observations remains to be determined.

During sepsis in children, studies show a significant increase in levels of soluble adhesion molecules [19,61-63]. Interestingly, Briassoulis and colleagues show significant increase of sE-selectin, as well as sL-selectin and ICAM-1, especially amongst survivors [19]. The authors conclude that inadequate or suppressed shedding during sepsis might be associated with increased mortality, and they hypothesize that the shedding process is indeed protective for the host. Similarly, in a large pediatric ICU study on microcirculatory dysfunction in meningococcal sepsis in children, levels of sE-selectin, sVCAM-1 and sICAM-1, but not sP-selectin, were significantly increased in septic patients but negatively correlated with the degree of microcirculatory dysfunction (a measure of sepsis severity), as assessed by sublingual imaging [61].

\section{Adults}

Generally, basal levels of soluble adhesion molecules in adults are similar to or somewhat lower than those of neonates and children (Tables 2, 3, 4, 5 and 6 and Figure 3). All molecules show increase during sepsis, with sICAM-1 and sP-selectin exhibiting the greatest increases compared with neonates and children. Age group stratification in levels of soluble adhesion molecules in adults is limited. Rudloff and colleagues determined sICAM-1 levels in healthy adults between 18 and 65 years old and reported no age-dependent differences [79].

As discussed above, in a large number of clinical sepsis studies in adults, higher levels of soluble adhesion molecules were generally related to severity of disease and mortality, although statistically significant correlations could not be made [5,6,15-17,37,65-74,76-82]. Some studies imply an alternate interpretation of these levels. For example, clinical studies have demonstrated that septic adults with modest levels of soluble adhesion molecules (putatively reflecting inadequate/aberrant shedding) had poorer outcome and higher mortality than those with the highest levels $[22,83]$. Donnelly and colleagues found that critically 


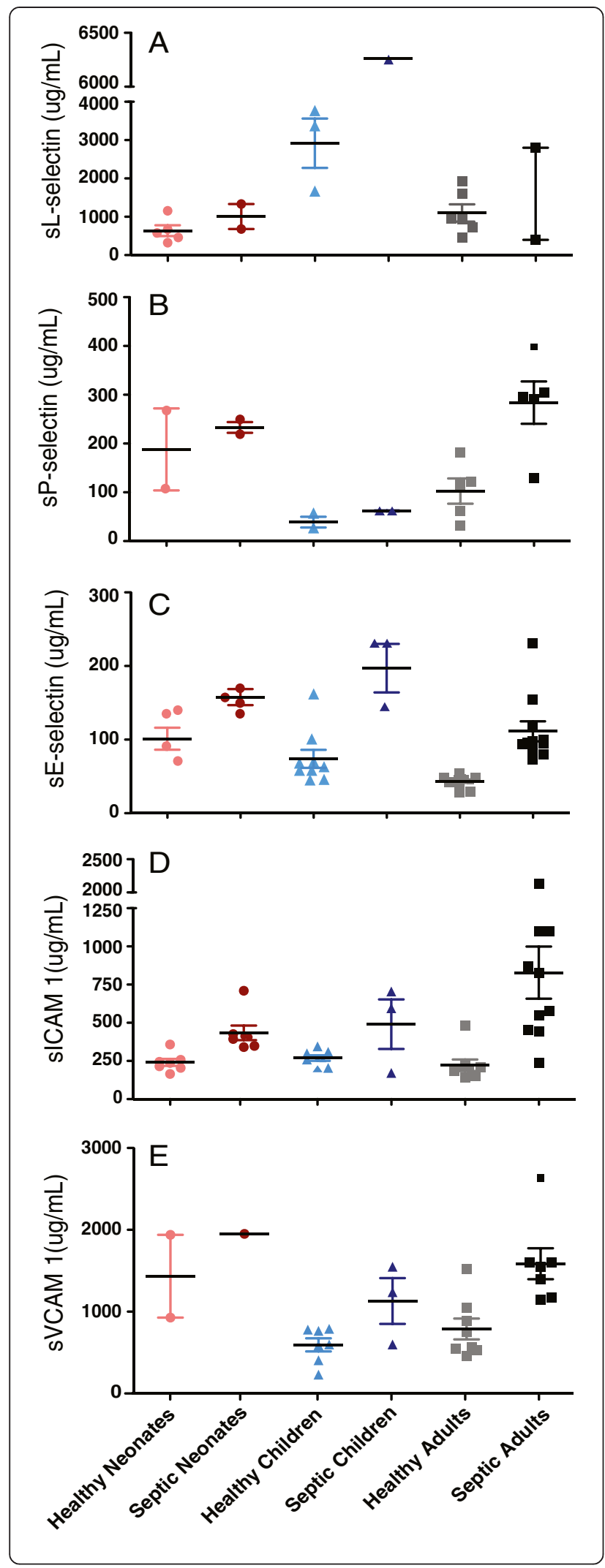

Figure 3 Levels of soluble E-selectin, L-selectin and P-selectin, intercellular adhesion molecule- 1 and vascular cell adhesion molecule- 1 in healthy and septic neonates, children and adults. Values of soluble adhesion molecules assessed in diverse clinical studies (see Tables 2, 3, 4, 5 and 6) plotted by adhesion molecule to graphically compare absolute and relative amounts in both healthy and septic subjects in distinct age groups. (A) Soluble L-selectin (sL-selectin). (B) Soluble P-selectin (sP-selectin). (C) Soluble Eselectin (sE-selectin). (D) Soluble intercellular adhesion molecule-1 (sICAM-1). (E) Soluble vascular cell adhesion molecule-1 (sVCAM-1).

ill patients with lower levels of sL-selectin had a higher chance of developing adult respiratory distress syndrome [83], and Seidelin and colleagues found that worse outcomes in septic patients correlated with lesser increases in sL-selectin levels [22]. Interestingly, one experimental study found significantly decreased leukocyteendothelial interaction in a murine cecal ligation model of sepsis upon addition of exogenous sL-selectin into the circulation at levels comparable with those found in septic adults [27].

\section{Adhesion molecule sheddases in sepsis: a delicate balance}

The levels of adhesion molecules are an indirect result of protein cellular expression levels and a direct result of the proteolytic activity of sheddases. Thus, as discussed above (for example, see [42-44]), expression and shedding activities can both independently contribute to overall levels of soluble adhesion molecules in circulation. Several studies have independently assessed levels of circulating sheddases and sheddase antagonists (that is, tissue inhibitor metalloproteinases) in clinical and experimental sepsis in efforts to clarify their contribution to pathology. However, so far these have yielded diverse and inconsistent results showing varied correlation of levels with protection and pathology [84-88], suggesting a delicate balance is required.

The sensitive relationship between levels/activity of sheddases and outcome/effects in the host during sepsis is best reflected by studies from Long and colleagues investigating the role of ADAM-17 in L-selectin shedding in murine sepsis $[12,89]$. They found that ADAM-17 in mice acts as a homeostatic (rheostat) molecule to control their neutrophil infiltration at sites of inflammation by regulating surface density of L-selectin. Low ADAM17 activity results in little L-selectin shedding and too much neutrophil infiltration with subsequent collateral tissue damage. However, excessive activity of ADAM-17 promotes excessive L-selectin shedding and subsequently impairs neutrophil infiltration, which is needed to clear inflammation and infection.

Finally, evidence of age-related changes in sheddases and sheddase antagonists (that is, tissue inhibitor 

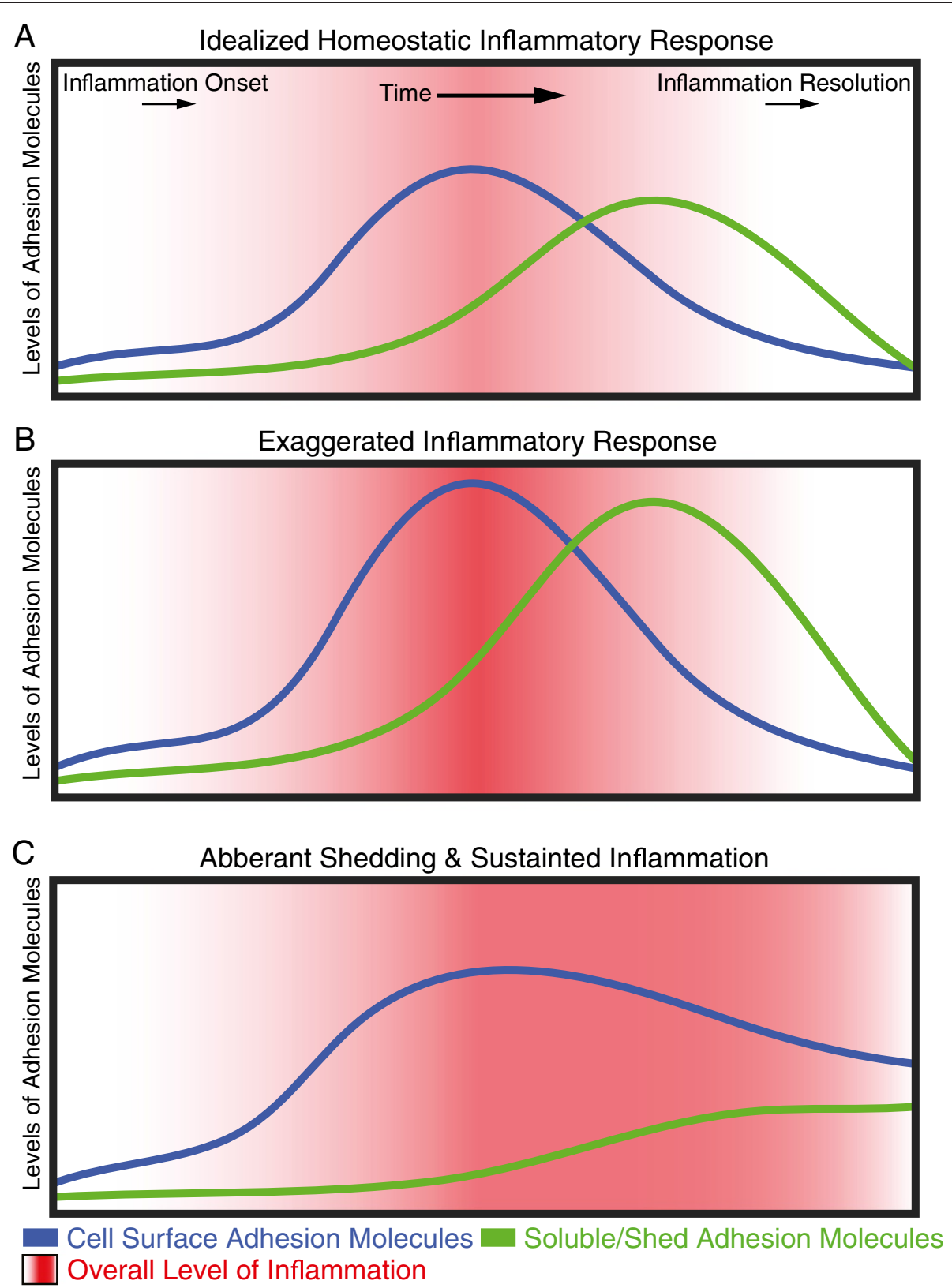

Figure 4 Changes in cell surface and circulating soluble adhesion molecules during progression of inflammatory responses. (A) Idealized homeostatic inflammatory response. Schematic showing the hypothetical increase in cell surface adhesion molecules (blue line) associated with onset of inflammation and the subsequent decrease in them during resolution of inflammation. Shedding and accumulation of circulating soluble adhesion molecules similarly rise and fall (green line), but with a lag in time. Points of highest levels of cell surface adhesion molecules (and not necessarily soluble adhesion molecules) should correlate with the greatest levels of overall inflammation and a propensity for collateral tissue damage (red shading). (B) Exaggerated inflammatory and response. Schematic as in (A) illustrating a more severe inflammation and greater initial cell surface adhesion molecule expression, and subsequently greater levels of soluble adhesion molecule production. (C) Aberrant shedding and sustained inflammation. Schematic as in (A) illustrating how a hypothetical deficiency in shedding during inflammation could lead to low levels of soluble adhesion molecules, leaving cell surface adhesion molecules elevated, and allowing for heightened and sustained inflammation.

metalloproteinases) has been observed. It is interesting to speculate that these differences could partially underlie the observed age-related discrepancies in levels of soluble adhesion molecules $[90,91]$.

\section{Conclusion}

Increased levels of soluble adhesion molecules generally correlate well with the presence of sepsis in neonates, children and adults. However, their levels are still poorly 
predictive of sepsis severity scores, outcome and mortality. Our review raises important issues that need further attention, including age-related discrepancies in soluble adhesion molecule levels and even basic questions about whether these should correlate positively or negatively with mortality.

First, there is a well-articulated hypothesis (and significant experimental support) that shedding is indeed principally a homeostatic process that works to reduce inflammation and promote resolution of inflammation (Figure 4). This is thought to act at two complementary levels: removal of adhesion molecules from cell surfaces directly reduces the ability for cell-cell interaction; and the resulting soluble isoforms serve as competitive antagonists (or decoy ligands) for the remaining cell surface adhesion molecules.

Second, there is substantial evidence that disruption of shedding during sepsis, resulting in substantially lower levels of soluble adhesion molecules (that is, retention of elevated cell surface adhesion molecule levels), could lead to exacerbation of inflammation or promotion of mortality (Figure 4C). Thus, as illustrated in Figure 4, there are many points during the progression of an inflammatory response whereby the functional significance (with respect to the severity of the underlying inflammation) of a given level of soluble adhesion molecule varies greatly. In addition, levels of sheddases are also altered in human and experimental sepsis, suggesting putative functional contribution for these changes in regulating disease progression. The interaction of adhesion molecules and sheddases in the dynamic microenvironment of the cellular surfaces implicates a strong interdependence of these molecules. However, to our knowledge, no studies exist that combine the assessment of both adhesion molecules and their sheddases to assess clinical outcome. Thus, a novel and potentially critical opportunity to enhance clinical efficacy of soluble adhesion molecules exists that remains untapped. Such a combinatorial approach might be particularly useful for improving both sepsis diagnosis (which is greatly needed for the challenging situations in the febrile neonate or extreme older person) and our ability to track efficacy of therapies. Furthermore, serial assessment of the combination of these markers might even be effective in determining morbidity or mortality risk. Finally, it is interesting to consider whether regulation of sheddases and adhesion molecules might be regulated in sepsis at the epigenetic level, potentially offering additional ways to assess disease severity and predict outcomes [92].

Additionally, the age-related and comorbidity-related heterogeneity in levels of soluble adhesion molecules, as well as sheddases, in healthy individuals and septic patients could be an expression of a different basal state, as well as different responsiveness in sepsis, potentially leading to discrepancies in pathophysiology and disease progression between neonates, children or adults. Interestingly, epidemiological research shows a biphasic pattern in age-related differences in incidence and mortality [2-4]. The incidence of neonatal sepsis is 1 to 8 per 1,000 live births with mortality rates of $16 \%$. These rates decrease during childhood (0.2/1,000 children, mortality $10 \%)$ and then increase in adults $(26.2 / 1,000$ in those over 85 years old, mortality 38.4\%) [2-4]. A direct correlation between these rates and levels of soluble adhesion molecules remains speculative, but further attention to this could provide new insights.

In conclusion, while predictive properties of soluble adhesion molecules have been researched intensively, their levels are still poorly predictive of sepsis outcome and mortality. We propose two novel directions for improving clinical utility of soluble adhesion molecules: the combined simultaneous analysis of levels of adhesion molecules and their sheddases; and taking age-related discrepancies into account. Additional investigation of these issues may provide better understanding of the pathophysiology of sepsis and increased usefulness of soluble adhesion molecules as diagnostic and predictive biomarkers.

\section{Abbreviations}

ADAM: a disintegrin and metalloproteinase; ICAM-1: intercellular adhesion molecule-1; sE-selectin: soluble E-selectin; sICAM-1: soluble intercellular adhesion molecule-1; sL-selectin: Soluble L-selectin; sP-selectin: Soluble P-selectin; sVCAM-1: soluble vascular cell adhesion molecule-1; VCAM-1: vascular cell adhesion molecule-1.

\section{Competing interests}

The authors declare that they have no competing interests.

\section{Authors' contributions}

RZ performed the literature search. RZ, RM, NIS, TWK, FBP and CVC helped draft and revise the manuscript. RZ and CVC prepared the figures. All authors helped to draft the manuscript. All authors read and approved the final manuscript.

\section{Acknowledgements}

RZ was supported by stipends from the Tergooi Hospitals, Blaricum, the Drie Lichten foundation, and the Ter Meulen Fund, Royal Netherlands Academy of Arts and Sciences and the IPRF Early Investigators Exchange Program Award of the European Society for Pediatric Research. CVC was supported by a grant from the National Institutes of Health (HL104006).

\section{Author details}

'Department of Pediatrics, Tergooi Hospitals, Blaricum, Postal Box 10016 Hilversum 1201 DA, The Netherlands. 'Department of Medicine, Center for Vascular Biology Research, Beth Israel Deaconess Medical Center, Harvard Medical School, Boston, 330 Brookline Avenue, RN-234, Boston, MA 02215, USA. ${ }^{3}$ Department of Pediatric Hematology, Immunology and Infectious Disease, Academic Medical Center, Meibergdreef 9, Amsterdam 1105 AZ, The Netherlands. ${ }^{4}$ Department of Emergency Medicine, Center for Vascular Biology Research, Beth Israel Deaconess Medical Center, Harvard Medical School, Boston, 330 Brookline Avenue, RN-234, Boston, MA 02215, USA.

\section{Published: 18 Feb 2014}

\section{References}

1. Dellinger RP, Carlet JM, Masur H, Gerlach H, Calandra T, Cohen J, Gea-Banacloche J, Keh D, Marshall JC, Parker MM, Ramsay G, Zimmerman JL, Vincent JL, Levy MM Surviving Sepsis Campaign Management Guidelines Committee: Surviving sepsis campaign guidelines for management of severe sepsis and septic shock. Crit Care Med 2004, 32:858-873. 
2. Lukacs SL, Schoendorf KC, Schuchat A: Trends in sepsis-related neonatal mortality in the United States. 1985-1998. Pediatr Infect Dis J 2004, 23:599-603.

3. Stoll BJ, Hansen NI, Sánchez PJ, Faix RG, Poindexter BB, Van Meurs KP, Bizzarro MJ, Goldberg RN, Frantz ID 3rd, Hale EC, Shankaran S, Kennedy K, Carlo WA, Watterberg KL, Bell EF, Walsh MC, Schibler K, Laptook AR, Shane AL, Schrag SJ, Das A, Higgins RD, Eunice Kennedy Shriver National Institute of Child Health and Human Development Neonatal Research Network: Early onset neonatal sepsis: the burden of group B-streptococcal and E. coli disease continues. Pediatrics 2011, 127:817-826.

4. Angus DC, Linde-Zwirble WT, Lidicker J, Clermont G, Carcillo J, Pinsky MR: Epidemiology of severe sepsis in the United States: analysis of incidence, outcome, and associated costs of care. Crit Care Med 2001, 29:1303-1310.

5. Aird WC: The role of the endothelium in severe sepsis and multiple organ dysfunction syndrome. Blood 2003, 101:3765-3777.

6. Shapiro NI, Schuetz P, Yano K, Sorasaki M, Parikh SM, Jones AE, Trzeciak S, Ngo L, Aird WC: The association of endothelial cell signalling, severity of illness, and organ dysfunction in sepsis. Crit Care 2010, 14:R182.

7. Carman CV, Springer TA: Trans-cellular migration: cell-cell contacts get intimate. Curr Opin Cell Biol 2008, 20:533-534.

8. Springer TA: Adhesion receptors of the immune system. Nature 1990, 346:425-433.

9. Springer TA: Traffic signals for lymphocyte recirculation and leukocyte emigration: the multi-step paradigm. Cell 1994, 76:301-314.

10. Garton KJ, Gough PJ, Raines EW: Emerging roles for ectodomain shedding in the regulation of inflammatory responses. J Leukoc Biol 2006, 79:1105-1116.

11. Xing K, Murthy S, Liles WC, Singh JM: Clinical utility of biomarkers of endothelial activation in sepsis - a systematic review. Crit Care 2012, $16:$ R7.

12. Long C, Wang $Y$, Herrera AH, Horiuchi $K$, Walcheck B: In vivo role of leukocyte ADAM17 in the inflammatory and host responses during $\mathrm{E}$. coli-mediated peritonitis. J Leukoc Biol 2010, 87:1097-1101.

13. Ley K, Laudanna C, Cybulsky MI, Nourshargh S: Getting to the site of inflammation: the leukocyte adhesion cascade updated. Nat Rev Immunol 2007, 7:678-689

14. Harrington EO, Stefanec T, Newton J, Rounds S: Release of soluble E-selectin from activated endothelial cells upon apoptosis. Lung 2006, 184:259-266.

15. Pigot $R$, Dillon $L P$, Hemingway $H$, Gearing $A J$ : Soluble forms of E-selectin, ICAM-1 and VCAM-1 are present in the supernatants of cytokine activated cultured endothelial cells. Biophys Res Commun 1992, 187:584-589.

16. Newman W, Beall LD, Carson CW, Hunder GG, Graben N, Randhawa ZI, Gopal TV, Wiener-Kronish J, Matthay MA: Soluble E-selectin is found in supernatants of activated endothelial cells and is elevated in the serum of patients with septic shock. J Immunol 1993, 150:644-654.

17. Cummings CJ, Sessler CN, Beall LD, Fisher BJ, Best AM, Fowler AA 3rd: Soluble E-selectin levels in sepsis and critical illness. Correlation with infection and hemodynamic dysfunction. Am J Respir Crit Care Med 1997, 156:431-437.

18. Smith CW: Potential significance of circulating E-selectin. Circulation 1997, 95:1986-1988.

19. Briassoulis G, Papassotiriou I, Mavrikiou M, Lazaropoulou C, Margeli A: Longitudinal course and clinical significance of TGF-beta1, sL- and sE-Selectins and SICAM-1 levels during severe acute stress in children. Clin Biochem 2007, 40:299-304.

20. Smalley DM, Ley K: L-selectin: mechanisms and physiological significance of ectodomain cleavage. J Cell Mol Med 2005, 9:255-266.

21. Venturi GM, Tu L, Kadono T, Khan Al, Fujimoto Y, Oshel P, Bock CB, Miller AS, Albrecht RM, Kubes P, Steeber DA, Tedder TF: Leukocyte migration is regulated by L-selectin endoproteolytic release. Immunity 2003, 19:713-724

22. Seidelin JB, Nielsen $\mathrm{OH}$, Strøm J: Soluble L-selectin levels predict survival in sepsis. Intensive Care Med 2002, 28:1613-1618.

23. Schleiffenbaum B, Spertini O, Tedder TF: Soluble L-selectin is present in human plasma at high levels and retains functional activity. J Cell Biol 1992, 119:229-238

24. Ferri LE, Pascual J, Seely AJ, Chaudhury P, Christou NV: Soluble L-selectin attenuates tumor necrosis factor-a-mediated leukocyte adherence and vascular permeability: a protective role for elevated soluble L-selectin in sepsis. Crit Care Med 2002, 30:1842-1847.

25. Ferri LE, Swartz D, Christou NV: Soluble L-selectin at levels present in septic patients diminishes leukocyte-endothelial cell interactions in mice in vivo: a mechanism for decreased leukocyte delivery to remote sites in sepsis. Crit Care Med 2001, 29:117-122.
26. Ferri LE, Chia S, Benay C, Giannias B, Christou NV: L-selectin shedding in sepsis limits leukocyte mediated microvascular injury at remote sites. Surgery 2009, 145:384-391.

27. Easton AS, Dorovini-Zis K: The kinetics, function, and regulation of P-selectin expressed by human brain microvessel endothelial cells in primary culture. Microvasc Res 2001, 62:335-345.

28. Zarbock A, Polanowska-Grabowska RK, Ley K: Platelet-neutrophil interactions: linking haemostasis and inflammation. Blood Rev 2007, 21:99-111.

29. Fijnheer R, Frijns CJ, Korteweg J, Rommes H, Peters JH, Sixma JJ, Nieuwenhuis HK: The origin of P-selectin as a circulating plasma protein. Thromb Haemost 1997, 77:1081-1085.

30. Chen AY, Ha JN, Delano FA, Schmid-Schönbein GW: Receptor cleavage and P-selectin-dependent reduction of leukocyte adhesion in the spontaneously hypertensive rat. J Leukoc Biol 2012, 92:183-194.

31. Füth R, Dinh W, Nickl W, Bansemir L, Barroso MC, Bufe A, Sause A Scheffold T, Krahn T, Ellinghaus $P$, Lankisch M: Soluble P-selectin and matrix metalloproteinase 2 levels are elevated in patients with diastolic dysfunction independent of glucose metabolism disorder or coronary artery disease. Exp Clin Cardiol 2009, 14:76-79.

32. Mosad E, Elsayh Kl, Eltayeb AA: Tissue factor pathway inhibitor and P-selectin as markers of sepsis-induced non-overt disseminated intravascular coagulopathy. Clin Appl Thromb Hemost 2011, 17:80-87.

33. Tsakadze NL, Sithu SD, Sen U, English WR, Murphy G, D'Souza SE: Tumor necrosis factor-alpha-converting enzyme (TACE/ADAM-17) mediates the ectodomain cleavage of intercellular adhesion molecule-1 (ICAM-1). J Biol Chem 2006, 281:3157-3164.

34. Sultan S, Gosling M, Nagase H, Powell JT: Shear stress-induced shedding of soluble intercellular adhesion molecule-1 from saphenous vein endothelium. FEBS Lett 2004, 564:161-165.

35. Fiore E, Fusco C, Romero P, Stamenkovic I: Matrix metalloproteinase 9 (MMP-9/gelatinase B) proteolytically cleaves ICAM-1 and participates in tumor cell resistance to natural killer cell-mediated cytotoxicity. Oncogene 2002, 21:5213-5223.

36. Champagne B, Tremblay P, Cantin A, St Pierre Y: Proteolytic cleavage of ICAM-1 by human neutrophil elastase. J Immunol 1998, 161:6398-6405

37. van Griensven M, Probst C, Müller K, Hoevel P, Pape HC: Leukocyte-endothelial interactions via ICAM-1 are detrimental in polymicrobial sepsis. Shock 2006, 25:254-259.

38. Shapiro NI, Yano K, Sorasaki M, Fischer C, Shih SC, Aird WC: Skin biopsies demonstrate site-specific endothelial activation in mouse models of sepsis. J Vasc Res 2009, 46:495-502.

39. Lemaire LC, de Kruif MD, Giebelen IA, van Zoelen MA, van't Veer C, van der Poll T: Differential dose-dependent effects of prednisolone on shedding of endothelial adhesion molecules during human endotoxemia. Immunol Lett 2008, 21:93-96.

40. Singh RJ, Mason JC, Lidington EA, Edwards DR, Nuttall RK, Khokha R, Knauper V, Murphy G, Gavrilovic J: Cytokine stimulated vascular cell adhesion molecule-1 (VCAM-1) ectodomain release is regulated by TIMP-3. Cardiovasc Res 2005, 67:39-49.

41. Newby AC: Studying mechanisms underlying shedding of endothelial membrane proteins could help patients at risk for myocardial infarction. Cardiovasc Res 2005, 67:4-5.

42. Koenig JM, Simon J, Anderson DC, Smith E, Smith CW: Diminished soluble and total cellular L-selectin in cord blood is associated with its impaired shedding from activated neutrophils. Pediatr Res 1996, 39:616-621

43. Rebuck N, Gibson A, Finn A: Neutrophil adhesion molecules in term and premature infants: normal or enhanced leucocyte integrins but defective L-selectin expression and shedding. Clin Exp Immunol 1995, 101:183-189.

44. Török C, Lundahl J, Hed J, Lagercrantz H: Diversity in regulation of adhesion molecules (Mac-1 and L-selectin) in monocytes and neutrophils from neonates and adults. Arch Dis Child 1993, 68:561-565.

45. Austgulen R, Arntzen KJ, Haereid PE, Aag S, Døllner H: Infections in neonates delivered at term are associated with increased serum levels of ICAM-1 and E-selectin. Acta Pediatr 1997, 86:274-280.

46. Levy O: Innate immunity of the newborn: basic mechanisms and clinical correlates. Nat Rev Immunol 2007, 7:379-390.

47. Giannaki G, Rizos D, Xyni K, Sarandakou A, Protonotariou E, Phocas I, Creatsas G: Serum soluble E-and L-selectin in the very early neonatal period. Early Hum Develop 2000, 60:149-155. 
48. Sitaru AG, Speer CP, Holzhauer S, Obergfell A, Walter U, Grossmann R: Chorioamnionitis is associated with increased CD40L expression on cord blood platelets. Thromb Haemost 2005, 94:1219-1223.

49. Figueras-Aloy J, Gómez-López L, Rodríguez-Miguélez JM, Salvia-Roiges MD, Jordán-García I, Ferrer-Codina I, Carbonell-Estrany X, Jiménez-González R: Serum soluble ICAM-1, VCAM-1, L-selectin and P-selectin levels as markers of infection and their relation to clinical severity in neonatal sepsis. Am J Perinat 2007, 24:331-338

50. Kourtis AP, Lee FK, Stoll BJ: Soluble L-selectin, a marker of immune activation, in neonatal infection. Clin Immunol 2003, 109:224-228.

51. Berner R, Niemeyer CM, Leititis JU, Funke A, Schwab C, Rau U, Richter K, Tawfeek MS, Clad A, Brandis M: Plasma levels and gene expression of granulocyte colony-stimulating factor, tumor necrosis factor-(alpha), interleukin (IL)-1(beta), IL-6, IL-8, and soluble intercellular adhesion molecule-1 in neonatal early onset sepsis. Pediatr Res 1998, 44:469-477.

52. Dollner $H$, Vatten $L$, Austgulen R: Early diagnostic markers for neonatal sepsis: comparing C-reactive protein, interleukin-6, soluble tumor necrosis factor receptors and soluble adhesion molecules. J Clin Epidemiol 2001, 54:1251-1257.

53. Hansen AB, Verder $H$, Staun-Olsen P: Soluble intercellular adhesion molecule and C-reactive protein as early markers of infection in newborns. J Perinat Med 2000, 28:97-103.

54. Edgar JDM: Serum sICAM-1 levels in the diagnosis of neonatal infection. Pediatr Res 1998, 44:430.

55. Edgar JDM, Wilson DC, McMillan SA, Crockard AD, Halliday MI, Gardiner KR, Rowlands BJ, Halliday HL, McNeill TA: Predictive value of soluble immunological mediators in neonatal infection. Clin Sci 1994, 87:165.

56. Edgar JDM, Gabriel V, Craig A, Wheeler D, Thomas M, Grant J: A low serum sICAM-1 level may assist in the exclusion of neonatal infection. Biol Neonate 2002, 81:105-108.

57. Edgar JDM, Gabriel V, Gallimore JR, McMillan SA, Grant J: A prospective study of the sensitivity, specificity and diagnostic performance of soluble intercellular adhesion molecule 1, highly sensitive C-reactive protein, soluble E-selectin and serum amyloid $\mathrm{A}$ in the diagnosis of neonatal infection. BMC Pediatr 2010, 16:10-22.

58. Apostolou M, Dimitriou H, Kaleyias J, Perdikogianni C, Stiakaki E, Costalos C, Kalmanti MC: Levels of soluble ICAM-1 in premature and full-term neonates with infection. Mediators Inflamm 2002, 11:95-98.

59. Kourtis AP, Nesheim SR, Thea D, Ibegbu C, Nahmias AJ, Lee FK: Correlation of virus load and soluble L-selectin, a marker of immune activation, in pediatric HIV infection. AIDS 2000, 14:2429-2436.

60. Andrys C, Pozler O, Krejsek J, Derner V, Drahosová M, Kopecký O: Serum soluble adhesion molecules (sICAM-1, sVCAM and E-selectin) in healthy school aged children and adults. Acta Medica (Hradec Kralove) 2000, 43:103-106.

61. Paize F, Sarginson R, Makwana N, Baines PB, Thomson AP, Sinha I, Hart CA, Riordan A, Hawkins KC, Carrol ED, Parry CM: Changes in the sublingual microcirculation and endothelial adhesion molecules during the course of severe meningococcal disease treated in the paediatric intensive care unit. Intensive Care Med 2012, 38:863-871.

62. Krueger $M$, Heinzmann A, Nauck M: Adhesion molecules in pediatric intensive care patients with organ dysfunction syndrome. Int Care Med 2007, 33:359-363.

63. Whalen MJ, Doughty LA, Carlos TM, Wisniewski SR, Kochanek PM, Carcillo JA: Intercellular adhesion molecule-1 and vascular cell adhesion molecule- 1 are increased in the plasma of children with sepsis-induced multiple organ failure. Crit Care Med 2000, 28:2600-2607.

64. Nash MC, Wade AM, Shah V, Dillon MJ: Normal levels of soluble E-selectin, soluble intercellular adhesion molecule-1 (sICAM-1), and soluble vascular adhesion molecule-1 (sVCAM-1) decrease with age. Clin Exp Immunol 1996, 103:167-170

65. Presterl E, Lassnigg A, Mueller-Uri P, El-Menyawi I, Graninger W: Cytokines in sepsis due to Candida albicans and in bacterial sepsis. Eur Cytokine Netw 1999, 10:423-430.

66. Weigand MA, Schmidt H, Pourmahmoud M, Zhao Q, Martin E, Bardenheuer HJ: Circulating intercellular adhesion molecule-1 as an early predictor of hepatic failure in patients with septic shock. Crit Care Med 1999, 27:2656-2661.

67. Hynninen M, Valtonen M, Markkanen H, Vaara M, Kuusela P, Jousela I, Piilonen A, Takkunen O: Interleukin 1 receptor antagonist and E-selectin concentrations: a comparison in patients with severe acute pancreatitis and severe sepsis. J Crit Care 1999, 14:63-68.
68. Knapp S, Thalhammer F, Locker GJ, Laczika K, Hollenstein U, Frass M, Winkler S, Stoiser B, Wilfing A, Burgmann H: Prognostic value of MIP-1a, TGF- $\beta 2$, sELAM-1, and SVCAM-1 in patients with gram-positive sepsis. Clin Immunol Immunopathol 1998, 7:139-144.

69. Osmanovic N, Romijn FP, Joop K, Sturk A, Nieuwland R: Soluble selectins in sepsis: microparticle-associated, but only to a minor degree. Thromb Haemost 2000, 84:731-732.

70. Soderquist B, Sundqvist KG, Vikerfors T: Adhesion molecules E-selectin, intercellular adhesion molecules-1 (ICAM-1) and vascular cell adhesion molecule-1 (VCAM-1) in sera from patients with Staphylococcus aureus bacteremia with or without endocarditis. Clin Exp Immunol 1999, 118:408-411.

71. Takala A, Jousela I, Jansson SE, Olkkola KT, Takkunen O, Orpana A, Karonen $\mathrm{SL}$, Repo $\mathrm{H}$ : Markers of systemic inflammation predicting organ failure in community-acquired septic shock. Clin Sci (Lond) 1999, 97:529-538.

72. Geppert A, Zorn G, Karth GD, Haumer M, Gwechenberger M, Koller-Strametz J, Heinz G, Huber K, Siostrzonek P: Soluble selectins and the systemic inflammatory response syndrome after successful cardiopulmonary resuscitation. Crit Care Med 2000, 28:2360-2365.

73. De Pablo R, Monserrat J, Reyes E, Diaz D, Rodriguez-Zapata M, de la Hera A, Prieto A, Alvarez-Mon M: Circulating sICAM-1 and sE-selectin as biomarker of infection and prognosis in patients with systemic inflammatory response syndrome. Eur J Intern Med 2013, 24:132-138.

74. Kayal S, Jaïs JP, Aguini N, Chaudière J, Labrousse J: Elevated circulating E-selectin, intercellular adhesion molecule 1, and von Willebrand factor in patients with severe infection. Am J Respir Crit Care Med 1998, 157:776-784.

75. Doughty LA, Kaplan SS, Carcillo JA: Inflammatory cytokine and nitric oxide responses in pediatric sepsis and organ failure. Crit Care Med 1996, 24:1137-1143

76. Leone M, Boutière B, Camoin-Jau L, Albanèse J, Horschowsky N, Mège JL, Martin C, Dignat-George F: Systemic endothelial activation is greater in septic than in traumatic-hemorrhagic shock but does not correlate with endothelial activation in skin biopsies. Crit Care Med 2002, 30:808-814.

77. Scherpereel A, Depontieu F, Grigoriu B, Cavestri B, Tsicopoulos A, Gentina T, Jourdain M, Pugin J, Tonnel AB, Lassalle P: Endocan, a new endothelial marker in human sepsis. Crit Care Med 2006, 34:532-537.

78. Hofer S, Brenner T, Bopp C, Steppan J, Lichtenstern C, Weitz J, Bruckner T, Martin E, Hoffmann U, Weigand MA: Cell death serum biomarkers are early predictors for survival in severe septic patients with hepatic dysfunction. Crit Care 2009, 13:R93.

79. Rudloff S, Thomas C, Kunz C: Variations of soluble intercellular cell adhesion molecule. Eur J Med Res 1995, 1:171-172.

80. Gearing $\mathrm{JH}$, Newman W: Circulating adhesion molecules in disease. Immunol Today 1993, 14:506-512

81. Pierrakos C, Vincent JL: Sepsis biomarkers: a review. Crit Care Med 2010, 14:15.

82. Schuetz $\mathrm{P}$, Jones AE, Aird WC, Shapiro NI: Endothelial cell activation in emergency department patients with sepsis-related and non-sepsis related hypotension. Shock 2011, 36:104-108.

83. Donnelly SC, Haslett C, Robertson CE, Carter DC, Ross JA, Grant IS, Tedder TF: Role of selectins in development of adult respiratory distress syndrome. Lancet 1994, 344:215-219.

84. Hoffmann U, Brueckmann M, Borggrefe M: Matrix metalloproteinases and their inhibitors: promising novel biomarkers in severe sepsis? Crit Care 2009, 13:1006

85. Lauhio A, Hästbacka J, Pettilä V, Tervahartiala T, Karlsson S, Varpula T, Varpula M, Ruokonen E, Sorsa T, Kolho E: Serum MMP-8, -9 and TIMP-1 in sepsis: high serum levels of MMP-8 and TIMP-1 are associated with fatal outcome in a multicentre, prospective cohort study. Hypothetical impact of tetracyclines. Pharmacol Res 2011, 64:590-594.

86. Lorente L, Martín MM, Labarta L, Díaz C, Solé-Violán J, Blanquer J, Orbe J, Rodríguez JA, Jiménez A, Borreguero-León JM, Belmonte F, Medina JC, Llimiñana MC, Ferrer-Agüero JM, Ferreres J, Mora ML, Lubillo S, Sánchez M, Barrios Y, Sierra A, Páramo JA: Matrix metalloproteinase-9, -10, and tissue inhibitor of matrix metalloproteinases-1 blood levels as biomarkers of severity and mortality in sepsis. Crit Care 2009, 13:R158.

87. Yazdan-Ashoori P, Liaw P, Toltl L, Webb B, Kilmer G, Carter DE, Fraser DD Elevated plasma matrix metalloproteinases and their tissue inhibitors in patients with severe sepsis. J Crit Care 2011, 26:556-565.

88. Belaaouaj A, McCarthy R, Baumann M, Gao Z, Ley TJ, Abraham SN, Shapiro SD: Mice lacking neutrophil elastase reveal impaired host defense against gram negative bacterial sepsis. Nat Med 1998, 4:615-618. 
89. Long C, Hosseinkhani MR, Wang Y, Sriramarao P, Walcheck B: ADAM17 activation in circulating neutrophils following bacterial challenge impairs their recruitment. J Leukoc Biol 2012, 92:667-672.

90. Bonnema DD, Webb CS, Pennington WR, Stroud RE, Leonardi AE, Clark LL, McClure CD, Finklea L, Spinale FG, Zile MR: Effects of age on plasma matrix metalloproteinases (MMPs) and tissue inhibitor of metalloproteinases (TIMPs). J Card Fail 2007, 13:530-540.

91. Tayebjee MH, Lip GY, Blann AD, Macfadyen RJ: Effects of age, gender, ethnicity, diurnal variation and exercise on circulating levels of matrix metalloproteinases (MMP)-2 and -9 , and their inhibitors, tissue inhibitors of matrix metalloproteinases (TIMP)-1 and -2. Thromb Res 2005, 115:205-210.

92. Graves BT, Munro CL: Epigenetics in critical illness: a new frontier. Nurs Res Pract 2013, 2013:503686.

\section{$10.1186 / \mathrm{cc} 13733$}

Cite this article as: Zonneveld et al: Soluble adhesion molecules as markers for sepsis and the potential pathophysiological discrepancy in neonates, children and adults. Critical Care 2014, 18:204 